\title{
Ocenet Consulta, base de datos en línea para bibliotecas públicas y universitarias
}

\author{
Por Jordi Grau Moracho y Javier Guallar Delgado
}

\begin{abstract}
DESDE SU PRESENTACIÓN pública en septiembre de 2002, la base de datos Ocenet Consulta, del grupo editorial Océano, está presente en un número creciente de bibliotecas públicas y universitarias de España, América Latina y Estados Unidos, distribuida en este último país por Gale.
\end{abstract}

\section{Características de Ocenet Consulta}

Es una base de datos que ofrece acceso a través de internet a información extraída de obras de referencia, artículos de revistas y fuentes primarias. Cuenta con más de 200 mil páginas digitalizadas que se van actualizando y se prevé la incorporación de nuevos documentos a un ritmo de 1.000 páginas al día de promedio durante el primer año. De comercialización exclusiva para bibliotecas, sus responsables la definen como un producto de amplio espectro dirigido a bibliotecas públicas y universitarias.

Los contenidos están diseñados para un público de entre quince y veinte años. La decisión de
Javier Guallar

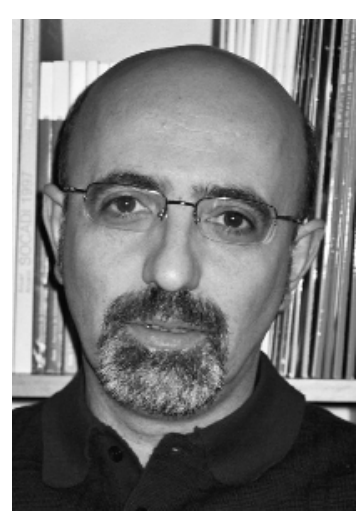

Jordi Grau

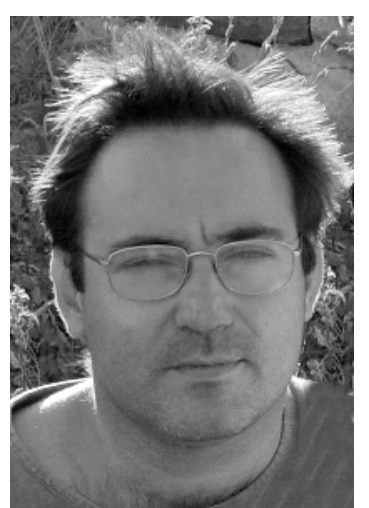

crear una base de datos pensada para esta franja de edad se debe al hecho de que se trata de un sector de la población muy desatendido en recursos informativos electróni- 
cos, para el que sólo existen los buscadores de internet. neral del área digital de Océano, explica que los documentos, que provienen en su mayoría del fondo editorial de Océano pero también de Gale y de terceros, se pasan de formato txt a xml y se les asignan descriptores. Posteriormente se integran en la base de datos para ser recuperados por el motor de búsqueda, que indaga sucesivamente en los descriptores, título, resumen $\mathrm{y}$ texto completo.

El motor es un desarrollo propio realizado con tecnología de $\mathrm{Ve}$ rity, que indexa los contenidos sobre una base de datos Oracle. El sistema utiliza tanto operadores booleanos como la acotación temática, y en estos momentos se está trabajando para integrar un tesauro y los operadores de proximidad. Otro aspecto que se está desarrollando es la integración de la base de datos con el opac. La intención es que las búsquedas en los catálogos de las bibliotecas se puedan cruzar con las búsquedas en $\mathrm{Oce}$ net Consulta en los dos sentidos.

\section{Nacimiento y desarrollo}

Andrés Usón, director de marketing de Océano, comenta que el
Ignacio Pascual, director ge-

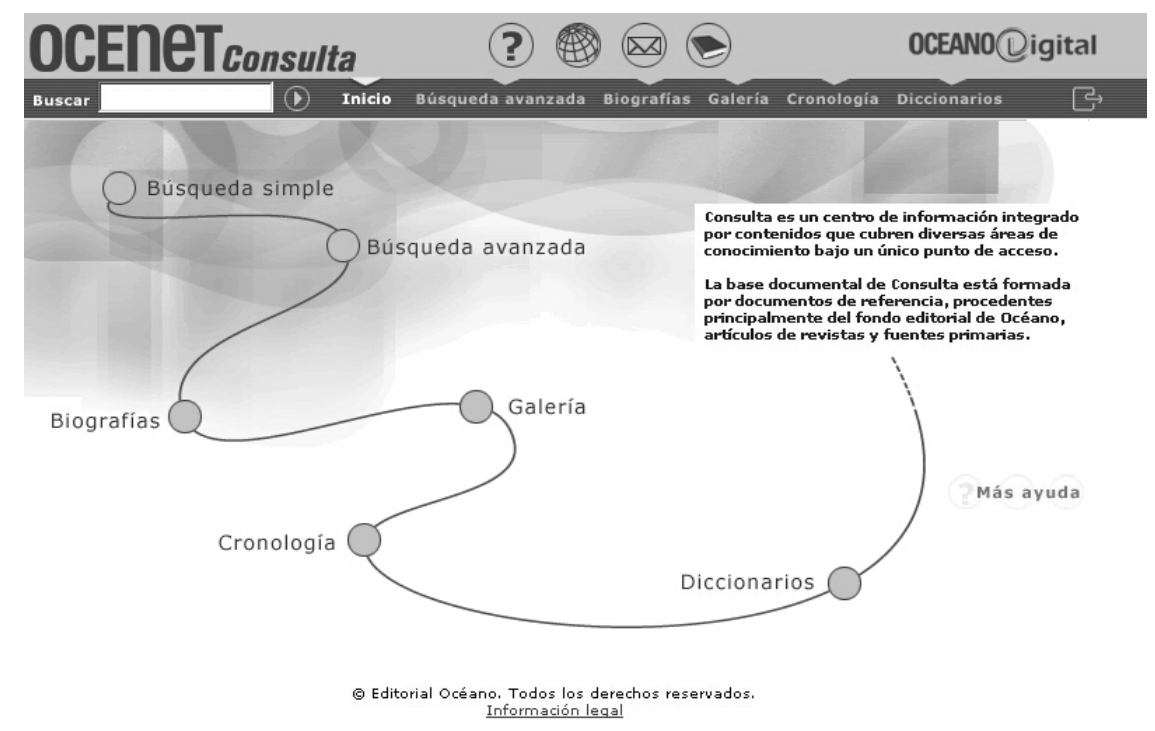

La pantalla principal muestra las diferentes opciones de búsqueda proyecto de crear una base de datos digital con las características mencionadas nació hace dos años como un acuerdo entre Océano y Gale. La idea inicial era aprovechar los puntos fuertes de cada empresa: Gale aportaría plataforma y know how, y Océano contenidos y red de distribución. Posteriormente, tras la integración de Gale en el grupo Thomson se produjo un cierto estancamiento en el desarrollo del producto, ante lo cual Océano asumió su creación íntegra con una inversión de 10 millones de euros, mientras que Gale se ha encargado finalmente de su distribución en el mercado norteamericano.

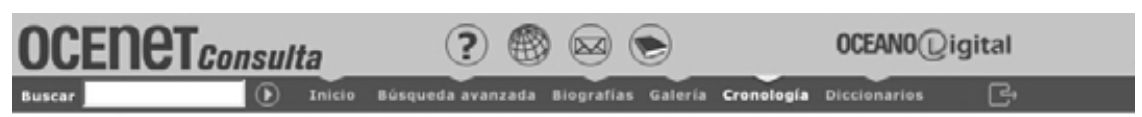

\section{Cronología}

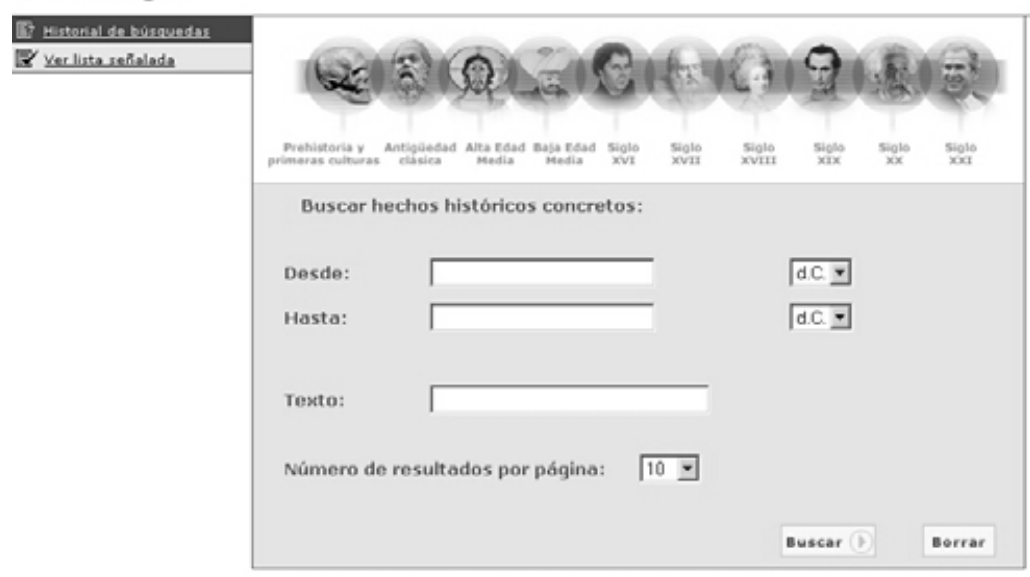

Pantalla de búsqueda cronológica
La presentación oficial de Ocenet Consulta tuvo lugar en septiembre de 2002 en la Biblioteca Nacional de España, y en los meses siguientes se llevó a diversos países de América Latina. Por su parte, Gale presentó el producto a los profesionales norteamericanos en el Midwinter Meeting de la American Library Association en febrero de $2003^{1}$.

Esta rápida introducción en Estados Unidos de una creación digital desarrollada en España subraya la importancia que tiene el mercado estadounidense en español, con una población hispanoparlante que utiliza en número creciente las bibliotecas y está demandando productos de información en su lengua.

Una treintena de bibliotecas y redes bibliotecarias había adquirido Ocenet Consulta hasta abril de 2003, según datos facilitados por Ignacio Abelló, de Océano. De las mismas, trece son bibliotecas españolas, diez de México, una de República Dominicana y seis de Estados Unidos. Entre todas ellas podemos citar: la $B N E$, las bibliotecas de la Diputació de Barcelona, las de las universidades de les Illes Balears y Salamanca (en España); las universidades Autónoma Metropolitana, Autónoma de la Baja California del Sur y las bibliotecas públicas de Mérida y Yucatán (en 
México); las bibliotecas públicas del Estado de Washington, Los Angeles, Miami y la red de bibliotecas de New Jersey (en Estados Unidos).

\section{Contenidos y opciones de búsqueda}

Ocenet Consulta contiene tres grupos diferenciados de documentos: contenidos de referencia, con 110.000 páginas extraídas de 100 obras de referencia (Diccionario Literario Bompiani, Diccionario de Biografías, Gran Enciclopedia Interactiva Océano Temática, Geografía Universal Gallach, Historia de la Humanidad, Gran Crónica Océano del Siglo XX, Historia del Arte Gallach, entre otras); artículos de revistas, con 50.000 artículos de 60 revistas (Lateral, Quimera, Alambique, Astrágalo, Américas, National Geographic en Español, etc.); y fuentes primarias, con 2.500 copias de documentos originales (El Quijote, el Diario del primer viaje a América de Cristóbal Colón, el Auto de detención dictado por el juez Baltasar Garzón a Augusto Pinochet, etc.).

De los tres tipos de fuentes el bloque principal es el constituido

\section{Primer proyecto digital de Océano}

Ocenet Consulta es el primer proyecto del área digital de Océano, editorial con sede en Barcelona que cuenta con una fuerte implantación en todos los países de América Latina, donde realiza el $90 \%$ de sus ventas. Su negocio fundamental ha sido hasta el momento la venta de obras de referencia a plazos, $y$ en segundo lugar la distribución de contenidos de otras editoriales en América. Con este producto se introduce con fuerza en el sector de la información digital, campo en el que anuncia proyectos futuros relacionados con la información médica y empresarial.

por los contenidos de referencia. Son un fondo importante en volumen y variedad, que puede ser de gran utilidad para el público estudiantil. Por su parte, el fondo de revistas a texto completo, con una proporción al 50\% aproximadamente entre publicaciones editadas en España y América, tiene un alcance menor. Es un aspecto a mejorar. Finalmente, los documentos originales son una muestra limitada pero interesante de algunos textos literarios e históricos significativos. Considerando los contenidos de Ocenet Consulta en conjunto, se constata que su punto fuerte son las humanidades mientras que las ciencias tienen una presencia muy reducida.

En cuanto a las posibilidades de recuperación, el producto integra diversas opciones. La búsqueda simple permite buscar en el conjunto del fondo documental o por separado en los bloques de referencia, revistas y fuentes primarias. La búsqueda avanzada añade más posibilidades a la modalidad anterior: combinar hasta tres términos distintos mediante los operadores booleanos en los campos de título, autor, fuente y texto. Para las revistas, se puede delimitar un intervalo de fechas de publicación.

Podemos resaltar también que el sistema presenta algunas interesantes facilidades de gestión de los resultados: afinar la búsqueda, para realizar una nueva consulta entre los resultados obtenidos; revisar la búsqueda, que permite volver al formulario inicial para corregir al-

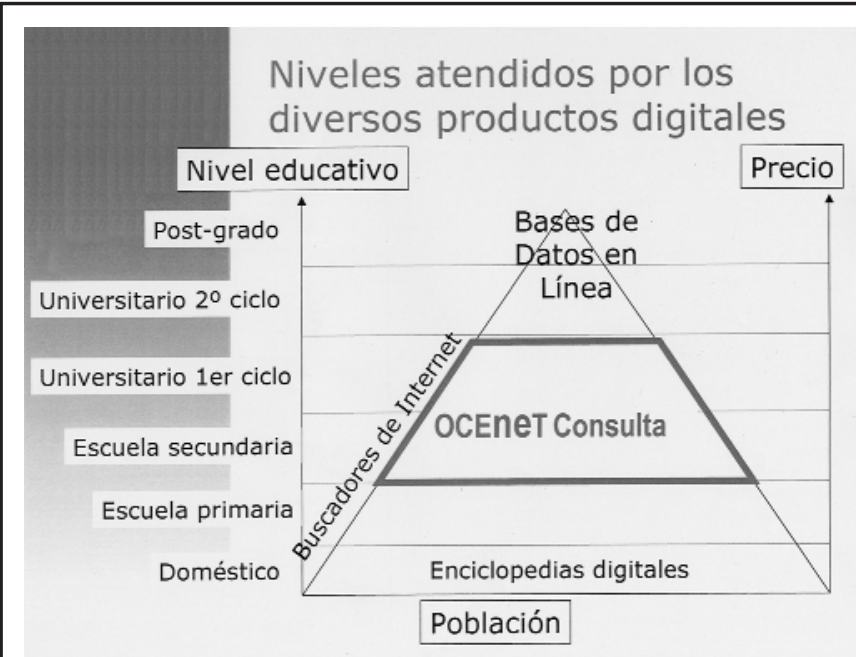

El cuadro muestra la relación entre diversas ofertas informativas digitales y el nivel educativo al que van dirigidas, en forma de pirámide poblacional estratificada. En él se aprecia el posicionamiento de Ocenet Consulta en la franja central.

Nivel inferior. La parte más baja de la pirámide está ocupada por un amplio sector de la población integrado por el campo doméstico y el de la escuela primaria, cubiertos básicamente por enciclopedias en cd y dvd y por buscadores de internet, productos gratuitos o de bajos precios.

Nivel central. A continuación se encuentra el segmento al cual se dirige Ocenet Consulta: la escuela secundaria y el primer ciclo universitario, franjas en las

que prácticamente sólo actúan los buscadores de internet.

Nivel superior. La parte más alta de la pirámide corresponde al nivel educativo más especializado, el del segundo ciclo universitario y superiores (postgrados, tercer ciclo, investigación), integrado por un grupo poblacional reducido pero que presenta un alto grado de consumo informativo, al cual van destinadas las bases de datos que habitualmente tienen precios más elevados. 
gún parámetro de la misma; y senalar los documentos que se consideren más interesantes entre la lista de resultados obtenida y añadirlos a una lista personal para su posterior consulta.

Otras opciones son las biografías y las cronologías. En el fondo biográfico el usuario puede interrogar por el nombre, la actividad, la nacionalidad, o la fecha y lugar de nacimiento o muerte o bien de realizar búsquedas de los personajes más relevantes por criterios combinados (época, país, género o actividad): por ejemplo, mujeres escritoras en España en el siglo XIX.

La búsqueda cronológica tiene dos modalidades. La primera muestra una línea de tiempo en la parte superior de la pantalla que da acceso a hechos enmarcados en grandes períodos de tiempo (Prehistoria y primeras culturas, Antigüedad clásica, Alta Edad Media, etc.), dentro de los ámbitos Historia y Política, Pensamiento y Religión, Descubrimientos y Exploraciones, Ciencia y Tecnología, Arte, Cultura y Sociedad. La segunda posibilidad consiste en buscar hechos históricos delimitados por los criterios fijados por el usuario: un período histórico o un texto concreto.

El sistema también integra una galería de imágenes que da acceso al fondo documental gráfico realizando las consultas por título y pie de foto, y una serie de diccionarios de lengua española, de sinónimos y antónimos, y bilingües de inglés-español, francés-español y alemán-español.
En definitiva, Ocenet Consulta es un recurso informativo en línea en lengua española, disponible en un creciente número de bibliotecas públicas y universitarias, y dirigido a jóvenes estudiantes entre 15 y 20 años, que destaca por su fondo de contenidos de referencia y su potencialidad de búsqueda.

http://ocenet.oceano.com

\section{Nota}

\footnotetext{
1. Quint, Barbara. "Consulta Spanish-language collection launched by Gale". En: Information today, 2003, 3 febrero. Consultado en: 214-03

http://www.infotoday.com/newsbreaks/nb03020 3-3.htm
}

\section{Jordi Grau Moracho}

jordi@grau.com

Javier Guallar Delgado

jguallard@uoc.edu 